\title{
Robust Sensorless Sliding Mode Flux Observer for DTC-SVM-based Drive with Inverter Nonlinearity Compensation
}

\author{
Ahriche Aimad ${ }^{\dagger}$, Kidouche Madjid*, and Saad Mekhilef** $^{*}$ \\ $\uparrow^{* *}$ Applied Automation Laboratory, Dept. of Automation, University of Boumerdes, Boumerdes, Algeria \\ ${ }^{* *}$ Power Electronics and Renewable Energy Research Laboratory, Dept. of Electrical Engineering, \\ University of Malaya, Kuala Lumpur, Malaysia
}

\begin{abstract}
This paper presents a robust and speed-sensorless stator flux estimation for induction motor direct torque control. The proposed observer is based on sliding mode approach. Stator electrical equations are used in the rotor orientation reference frame to eliminate the observer dependence on rotor speed. Lyapunov's concept for systems stability is adopted to confine the observer gain. Furthermore, the sensitivity of the observer to parameter mismatch is recovered with an adaptation technique. The nonlinearities of the pulse width modulation voltage source inverter are estimated and compensated to enhance stability at low speeds. Therefore, a new method based on the model reference adaptive system is proposed. Simulation and experimental results are shown to verify the feasibility and effectiveness of the proposed algorithms.
\end{abstract}

Keywords: Dead time compensation, Direct torque control, Induction motor, Sliding mode observer, Voltage source inverter

\section{INTRODUCTION}

Nowadays, manufacturers prefer to use induction motors in most applications thanks to the affordability and high performance of these motors. However, the use of these motors at variable operating modes (adjustable speed, torque control, etc.) requires voltage source inverters (VSIs). Thus, the conventional six-switch topology is widely used. The popularity of this topology is attributed to the introduction of advanced electronic devices (e.g., IGBT transistors, diodes) and high-speed microcontrollers (e.g., DSP, FPGA). On the other hand, the control techniques have been greatly evolved to improve their usefulness. One of the control techniques for AC drives is direct torque control (DTC) that employs space vector modulation (SVM). This technique is reliable and has a good performance because it offers low current total harmonic distortion (THD) and low torque ripple [1]-[3]. The

Manuscript received Jul. 26, 2013; revised Nov. 7, 2013

Recommended for publication by Associate Editor Sanjeet K. Dwivedi.

${ }^{\dagger}$ Corresponding Author: ahriche.a@gmail.com

Tel: +213-666-706504, University of Boumerdes

*Applied Automation Laboratory, Dept. of Automation, University of Boumerdes, Algeria

${ }^{* *}$ Power Electronics and Renewable Energy Research Laboratory, Dept. of Electrical Engineering, University of Malaya, Malaysia speed-sensorless approach is usually favored since it solves all sensor-delay problems and exhibits high accuracy at a wide speed range. Unfortunately, sensor replacement has several disadvantages, especially at very low speed and when the estimated speed depends on other observed quantities, such as rotor or stator fluxes. In this context, many studies have designed accurate estimators and introduced new sensorless schemes [4]-[20], including magnetic-saliency methods [4]-[7] (which present limitations in terms of precision and usefulness for low-saliency motors) and observer-based techniques [8]-[16] (which suffer from parameter mismatch, particularly at very low speeds and standstill operations). The artificial intelligence approach has been introduced recently to solve these problems [17]-[20]. However, their exigencies in real-time implementation make them unattractive. In this study, a speed-sensorless algorithm is designed based on the variable structure control (VSC) principle [32]. The rotor speed value is disregarded by considering all speed terms as disturbances. On the other hand, since the proposed drive is based on PWM-VSI, the inverter nonlinearities like dead time and the voltage drop across the power devices should be compensated. Many noteworthy solutions were implemented in [21]-[30]. The effects of nonlinearities on AC drive performance were depicted in most of these solutions, and several adaptive and 
non-adaptive compensation methods were proposed. In [30], nonlinearities were distinguished and compensated for separately; two different techniques were suggested for each type. Special attention also was provided to the compensation of measurement noises. A feed-forward current-based algorithm was discussed; this configuration significantly improves the current and voltage waveforms. Unfortunately, the proposed scheme did not function well in some variable load operating modes. Thus, a voltage feed-back scheme was introduced to enhance the feed-forward compensator. In fact, the challenges posed by turn ON/OFF variable delay were successfully overcome. However, the technique reduces the quality of the current and voltage at zero crossing. The voltage drop across switches was evaluated by considering semiconductor devices of the same characteristics. Despite the substantially minimized calculation, better result was attained when the diodes and transistors was considered with different characteristics.

In the present paper, a speed-sensorless sliding mode observer (SMO) is developed for stator flux estimation. The DTC-SVM principle is presented by a flux-linkage model. A SMO is then designed with only the stator electrical equations in the rotor orientation reference frame. Furthermore, in order to confine the observer gain under stability conditions, a candidate Lyapunov function is selected. Also, the stator resistance and rotor time-constant mismatch are discussed, and an adaptation method for rotor time-constant is adopted. In addition, a model reference adaptive system (MRAS) algorithm is proposed for nonlinearity estimation and compensation in PWM-VSI. Simulation and experiments are carried out with Matlab/Simulink and a TMS320F240 digital signal processor to verify the feasibility and the effectiveness of the whole proposed algorithm.

\section{SVM FOR INDUCTION MOTOR DIRECT TORQUE CONTROL}

In a vector-matrix representation, the induction motor dynamic can be described by a two-dimensional state space model with both stator flux and stator current as state variables [see Equation (1)]. All variables are referred to an arbitrary rotating reference frame denoted by $(e)$ [31].

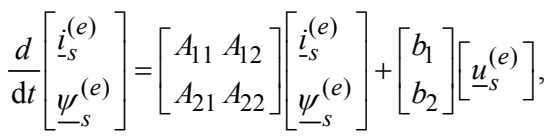

where $i_{s}$ and $\psi_{s}$ are the stator current and stator flux respectively, $u_{s}$ is the system input and $A_{11}, A_{12}, A_{21}, A_{22}, b_{1}$, $b_{2}$ are the matrix coefficients provided as follows:

$$
\begin{array}{ll}
A_{11}=-\left[\frac{1}{x_{s}^{\prime}}\left(R_{s}+\frac{x_{s}^{\prime}}{\sigma T_{r}}\right) I-\left(\omega_{r}-\omega_{e}\right) J\right] ; A_{21}=-R_{s} \omega_{b} I \\
A_{12}=-\frac{1}{x_{s}^{\prime}}\left(\omega_{r} J-\frac{1}{T_{r}} I\right) & ; A_{22}=-\omega_{e} J
\end{array}
$$

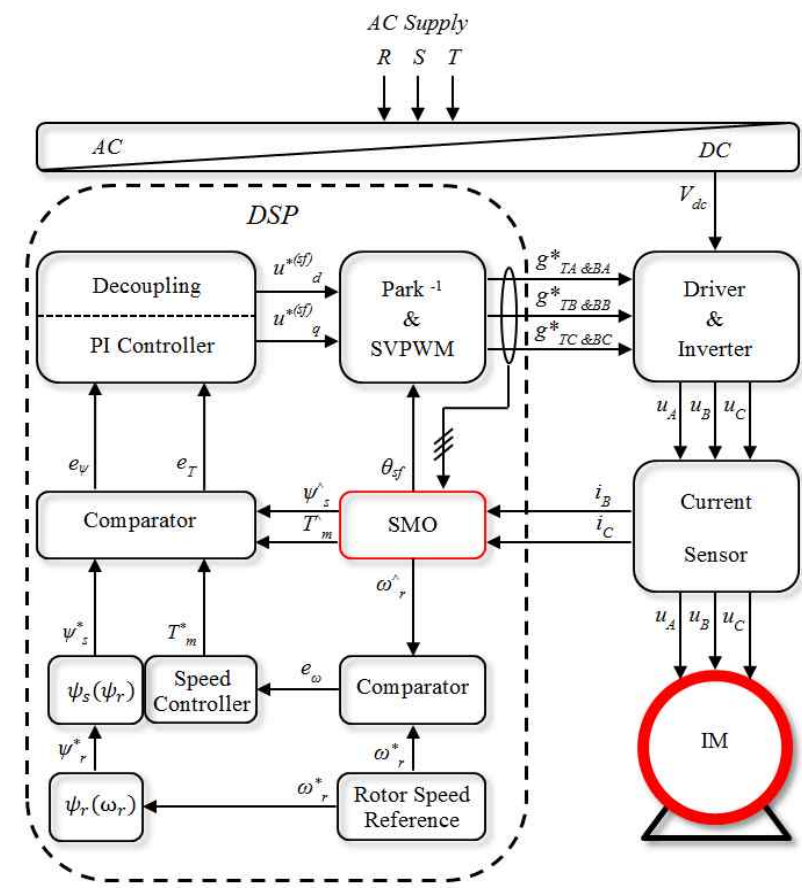

Fig. 1. Block diagram of the DTC-SVM-based induction motor drive.

$$
\begin{aligned}
& b_{1}=\frac{1}{x_{s}^{\prime}} I ; \quad b_{2}=\omega_{b} I ; I=\left[\begin{array}{ll}
1 & 0 \\
0 & 1
\end{array}\right] ; J=\left[\begin{array}{rr}
0 & -1 \\
1 & 0
\end{array}\right] \\
& T_{r}=\frac{x_{r}^{\prime}}{R_{r}^{\prime} \omega_{b}} ; \sigma=\left(1-\frac{x_{m}^{2}}{x_{s} x_{r}^{\prime}}\right) ; x_{s}^{\prime}=\frac{\sigma x_{s}}{\omega_{b}}
\end{aligned}
$$

$\omega_{b}, \omega_{r}$, and $\omega_{e}$ are the electrical pulsations of the base, rotor, and reference frame respectively. $R_{s}, R_{r}^{\prime}, x_{s}, x_{r}^{\prime}, x_{m}$ are the motor model parameters (see Appendix).

The motor torque value can be calculated as

$$
T_{m}^{(e)}=\frac{3}{2} \frac{P}{2 \omega_{b}}\left(\psi_{s d}^{(e)} i_{s q}^{(e)}-\psi_{s q}^{(e)} i_{s d}^{(e)}\right),
$$

where $P$ is the number of poles.

In induction motor DTC-SVM, both stator flux and motor torque can be directly controlled without any current control loop. Thus, it's offering fast dynamic and high efficiency. The control is mainly related to the synthesis of terminal voltage. Thus, the relationship between the motor terminal voltage components $\left(u_{s d}, u_{s q}\right)$ and both stator flux and motor torque must be determined. In stator flux orientation denoted by (sf), equations (1) and (2) become

$$
\left\{\begin{array}{l}
\psi_{s q}^{(s f)}=0 \\
\frac{\left.\mathrm{d} \psi_{s d}^{(s f}\right)}{\mathrm{d} t}=u_{s d}^{(s f)}-R_{s} \omega_{b} i_{s d}^{(s f)} \\
T_{m}^{(s f)}=\frac{3 P}{4 R_{s}} \psi_{s d}^{(s f)}\left(u_{s q}^{(s f)}-\omega_{s f} \psi_{s d}^{(s f)}\right)
\end{array},\right.
$$

where $\omega_{s f}$ is the referential frame angular speed. The block diagram of DTC-SVM for a speed-sensorless induction motor 
drive is shown in Fig. 1.

The commanded voltage components $u^{*(s)}$ and $u^{*(s f)}$ sq are synthesized separately using both stator flux and motor torque errors, respectively. For this purpose, two PI controllers are designed based on the classical pole-placement method employed in [34]. The estimated values of flux and torque are provided by a SMO, whereas the reference values are generated based on the speed profiles (the proposed scheme operates with constant rotor flux). Finally, the commanded voltage components are sent to an SVM block to synthesize the appropriate switching signals.

\section{SMO-BASED STATOR FLUX ESTIMATION}

A number of considerations must be introduced in the observer selection step depending on the available data and the important features of the control scheme. In the proposed scheme, the most significant challenge is the design of the inherently sensorless observer that can compensate for disturbances, such as motor parameter mismatch and measurement noises. Thus, several state variables and reference frames are analyzed. Both stator flux and stator current in the rotor frame are selected to identify the configuration that does not require rotor speed adaptation.

\section{A. SMO Design}

In the rotating reference frame fixed to the rotor, the induction motor formula in Equation (1) becomes

$$
\left\{\begin{array}{l}
x_{s}^{\prime} \frac{\mathrm{d} \underline{i}_{-s}^{(r)}}{\mathrm{d} t}=\underline{u}_{s}^{(r)}+\left(\frac{1}{T_{r}}-j \omega_{r}\right) \underline{\psi}_{s}^{(r)}-\left(R_{s}+\frac{x_{s}^{\prime}}{\sigma T_{r}}\right) \underline{i}_{s}^{(r)}, \\
\frac{\mathrm{d} \underline{\psi}_{s}^{(r)}}{\mathrm{d} t}=\omega_{b} \underline{u}_{s}^{(r)}-j \omega_{r} \underline{\psi}_{s}^{(r)}-R_{s} \omega_{b} \underline{i}_{-s}^{(r)}
\end{array},\right.
$$

Where ( $r$ ) denotes the rotor orientation of the reference frame. According to the sliding mode control principle [32] and assuming that all terms that contain the motor back-EMF $\left(j \omega_{r} \psi_{s}\right)$ are regarded as disturbances, if we consider the stator current as the system output, the full-order SMO based on Equation (4) can be expressed as follows:

$$
\left\{\begin{array}{l}
\hat{x}_{s}^{\prime} \frac{\mathrm{d} \hat{i}_{-s}^{(r)}}{\mathrm{d} t}=\underline{u}_{s}^{(r)}+\frac{1}{\hat{T}_{r}} \underline{\hat{\psi}}_{s}^{(r)}-\left(\hat{R}_{s}+\frac{\hat{x}_{s}^{\prime}}{\hat{\sigma} \hat{T}_{r}}\right) \hat{\hat{i}}_{s}^{(r)}-k_{c} f\left(e\left(\underline{i}_{s}^{(r)}\right)\right) \\
\frac{\mathrm{d} \hat{\psi}_{-}^{(r)}}{\mathrm{d} t}=\underline{\omega}_{b} u_{s}^{(r)}-\hat{R}_{s} \omega_{b} \hat{i}_{-s}^{(r)}-k_{c} f\left(e\left(\underline{i}_{-s}^{(r)}\right)\right)
\end{array}\right.
$$

The superscript $\left(\stackrel{\wedge}{)}\right.$ signifies estimated values, $k_{c}$ is the current observer gain, and $e_{i s}$ represents the current error given by

$$
e\left(i_{-s}^{(r)}\right)=\left[\begin{array}{l}
e\left(i_{s d}^{(r)}\right) \\
e\left(i_{s q}^{(r)}\right)
\end{array}\right]=\left[\begin{array}{l}
\left(k_{P}+k_{I} \int\right)\left(\hat{i}_{s d}^{(r)}-i_{s d}^{(r)}\right) \\
\left(k_{P}+k_{I} \int\right)\left(\hat{i}_{s q}^{(r)}-i_{s q}^{(r)}\right)
\end{array}\right] .
$$

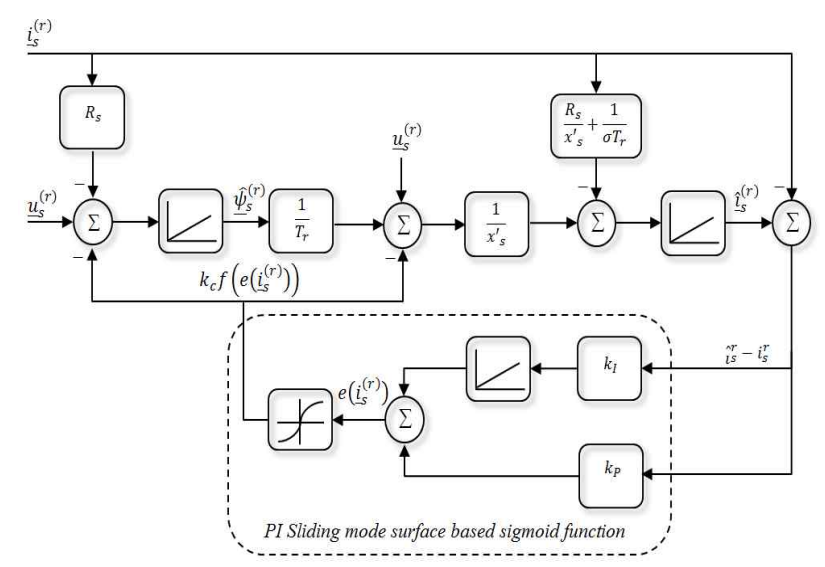

Fig. 2. Proposed SMO-based flux estimation.

The PI control was introduced here to handle the error convergence. A sigmoid function $(f)$ is employed instead of the traditional sign function in [10] to enhance the dynamics and reduce the chattering phenomena.

$$
f(\underline{x})=\left[\begin{array}{l}
f\left(x_{d}\right) \\
f\left(x_{q}\right)
\end{array}\right]=\left[\begin{array}{l}
\left(\frac{2}{1+e^{-a x} d}\right)-1 \\
\left(\frac{2}{1+e^{-a x} q}\right)-1
\end{array}\right],
$$

Where $(a)$ is an adjustable positive parameter used to tune the sigmoid function slope. The proposed scheme with a PI sliding mode surface and sigmoid function is illustrated in Fig. 2. The sliding mode mechanism is enclosed within a dashed rectangle.

\section{B. Stability Analysis}

To confine the value of $k_{c}$ under stability conditions, a candidate Lyapunov function is selected as follows:

$$
V=\frac{1}{2}\left(e\left(\underline{i}_{-s}^{(r)}\right)\right)^{T} e\left(\underline{i}_{-s}^{(r)}\right) .
$$

We assume that non-mismatch exists in the induction motor model parameters. By subtracting Equation (4) from Equation (5), the derivatives of the current and flux errors are obtained as

$$
\left\{\begin{array}{l}
\hat{x}_{s}^{\prime} \frac{\mathrm{d} e\left(\underline{i}_{-s}^{(r)}\right)}{\mathrm{d} t}=\frac{1}{T_{r}} e\left(\underline{\psi}_{S}^{(r)}\right)-\left(R_{s}+\frac{x_{s}^{\prime}}{\sigma T_{r}}\right) e\left(\underline{i}_{s}^{(r)}\right)+\underline{L}_{c}, \\
\frac{\mathrm{d} e\left(\underline{\psi}_{s}^{(r)}\right)}{\mathrm{d} t}=\underline{L}_{c}
\end{array},\right.
$$

where 


$$
\left\{\begin{array}{l}
e\left(\underline{\psi}_{s}^{(r)}\right)=\underline{\hat{\psi}}_{s}^{(r)}-\underline{\psi}_{s}^{(r)} \\
\underline{L}_{c}=j \omega_{r} \underline{\psi}_{s}^{(r)}-k_{c} f\left(e\left(\underline{i}_{s}^{(r)}\right)\right)
\end{array} .\right.
$$

Through the above equations, we can define the attractivity condition of the sliding surface as

$$
\frac{\mathrm{d} V}{\mathrm{~d} t}=\left(\frac{\mathrm{d} e\left(\underline{i}_{-s}^{(r)}\right)}{\mathrm{d} t}\right)^{T} e\left(\underline{i}_{-s}^{(r)}\right)<0 .
$$

By substituting Equation (9) in Equation (11), Lyapunov's function becomes

$$
\begin{aligned}
x_{s}^{\prime} \frac{\mathrm{d} V}{\mathrm{~d} t}= & x_{s}^{\prime}\left[\frac{\mathrm{d} e\left(i_{s d}^{(r)}\right)}{\mathrm{d} t} e\left(i_{s d}^{(r)}\right)+\frac{\mathrm{d} e\left(i_{s q}^{(r)}\right)}{\mathrm{d} t} e\left(i_{s q}^{(r)}\right)\right] \\
= & -\left(R_{s}+\frac{x_{s}^{\prime}}{\sigma T_{r}}\right)\left[\left(e\left(i_{s d}^{(r)}\right)\right)^{2}+\left(e\left(i_{s q}^{(r)}\right)\right)^{2}\right] \\
& +e\left(i_{s d}^{(r)}\right)\left[\frac{1}{T_{r}} e\left(\psi_{s d}^{(r)}\right)-\underline{L}_{1}\right] \\
& +e\left(i_{s q}^{(r)}\right)\left[\frac{1}{T_{r}} e\left(\psi_{s q}^{(r)}\right)+\underline{L}_{1}\right]<0 .
\end{aligned}
$$

Thus, when the sliding mode surface and its derivative reach zero, equation (12) is verified if

$$
k_{c}>\max \left(\left|\frac{1}{T_{r}} e\left(\psi_{s d}^{(r)}\right)-\omega_{r} \psi_{s q}^{(r)} \| \frac{1}{T_{r}} e\left(\psi_{s q}^{(r)}\right)+\omega_{r} \psi_{s d}^{(r)}\right|\right) .
$$

Overall, the sliding mode dynamics and its asymptotic stability are guaranteed when $k_{c}$ is sufficiently large. The flux error in Equation (9) becomes

$$
\frac{\mathrm{d} e\left(\underline{\psi}_{s}^{(r)}\right)}{\mathrm{d} t}=-\frac{1}{T_{r}} e\left(\underline{\psi}_{s}^{(r)}\right) .
$$

The ratio $\left(1 / T_{r}\right)$ represents the inverse of the rotor timeconstant which determines the dynamics of the flux observer.

\section{Rotor time-constant Adaptation}

The designed SMO is supposed to be robust in terms of parameter detuning and measurement noise reduction. However, the values of the stator and rotor time-constants may deviate widely because of the heating of the windings. This phenomenon will introduce errors in flux estimation and result in the inaccurate estimation of electromagnetic torque. The effects of stator resistance mismatch on the proposed SMO are omitted, since all terms that contain stator resistance in Equation (5) have the same gain and sign $\left(-\omega_{b} R_{s} i_{s}\right)$. Whereas, the rotor time-constant $T_{r}$ appears only in the current equation in (5). This can cause significant errors according to the rotor resistance variation. Thus, the adaptation of such parameter becomes necessary.

Under assumption that the rotor time-constant is variable, in sliding mode, the Equation (9) can be written as

$$
\left\{\begin{array}{l}
e\left(\underline{\psi}_{s}^{(r)}\right)=\frac{T_{r}}{\Delta T_{r}}\left(\underline{\hat{\psi}}_{S}^{(r)}-\frac{x_{s}^{\prime}}{\sigma} \underline{i}_{S}^{(r)}\right)+T_{r} \underline{L}_{c} \\
\frac{\mathrm{d} e\left(\underline{\psi}_{S}^{(r)}\right)}{\mathrm{d} t}=\underline{L}_{c}
\end{array}\right.
$$

where $\Delta T_{r}=\hat{T}_{r}-T_{r}$.

The new candidate Lyapunov function is considered as follows:

$$
V_{T_{r}}=\frac{1}{2}\left(e\left(\underline{\psi}_{s}^{(r)}\right)\right)^{T} e\left(\underline{\psi}_{s}^{(r)}\right)+\frac{k_{T_{r}}}{2}\left(\frac{1}{\Delta T_{r}}\right)^{2},
$$

where $k_{T r}$ is a positive constant. The derivative of Equation (16) is

$$
\frac{\mathrm{d} V_{T_{r}}}{\mathrm{~d} t}=\left(\frac{\mathrm{d} e\left(\underline{\psi}_{s}^{(r)}\right)}{\mathrm{d} t}\right)^{T} e\left(\underline{\psi}_{S}^{(r)}\right)+\frac{k_{T_{r}}}{\Delta T_{r}}\left(\frac{d}{\mathrm{~d} t} \frac{1}{\Delta T_{r}}\right) .
$$

Setting Equation (15) in Equation (17) yields

$$
\frac{\mathrm{d} V_{T_{r}}}{\mathrm{~d} t}=T_{r} \underline{L}_{c}^{T} \underline{L}_{c}+\frac{1}{\Delta T_{r}}\left(T_{r} \underline{L}_{c}^{T} \underline{H}+k_{T_{r}}\left(\frac{d}{\mathrm{~d} t} \frac{1}{\Delta T_{r}}\right)\right),
$$

where

$$
\underline{H}=\underline{\hat{\psi}}_{S}^{(r)}-\frac{x_{s}^{\prime}}{\sigma} i_{s}^{(r)} .
$$

In order to verify the second Lyapunov condition $\left(d V_{T} / d t<0\right)$, we write

$$
T_{r} \underline{L}_{c}^{T} \underline{L}_{c}<0
$$

and

$$
T_{r} \underline{L}_{c}^{T} \underline{H}+k_{T_{r}}\left(\frac{d}{\mathrm{~d} t} \frac{1}{\Delta T_{r}}\right)=0 .
$$

Finally, the rotor time-constant is online adapted as

$$
\frac{1}{\hat{T}_{r}}=\frac{1}{T_{r}}-\frac{T_{r}}{k_{T_{r}}} \int \underline{L}_{c}^{T} \underline{H} \mathrm{~d} t .
$$

\section{Speed and Motor Torque Estimation}

The real-time elaboration of the DTC-SVM requires knowledge of the rotor speed and motor torque instantaneous values. Therefore, a speed calculation method is implemented based on the flux estimated values.

$$
\hat{\omega}_{r}^{(s)}=\hat{\omega}_{s}^{(s)}-\hat{\omega}_{\text {slip }}^{(s)},
$$

where $\omega_{\text {slip }}$ is the slip speed and $\omega_{s}$ is calculated using the 


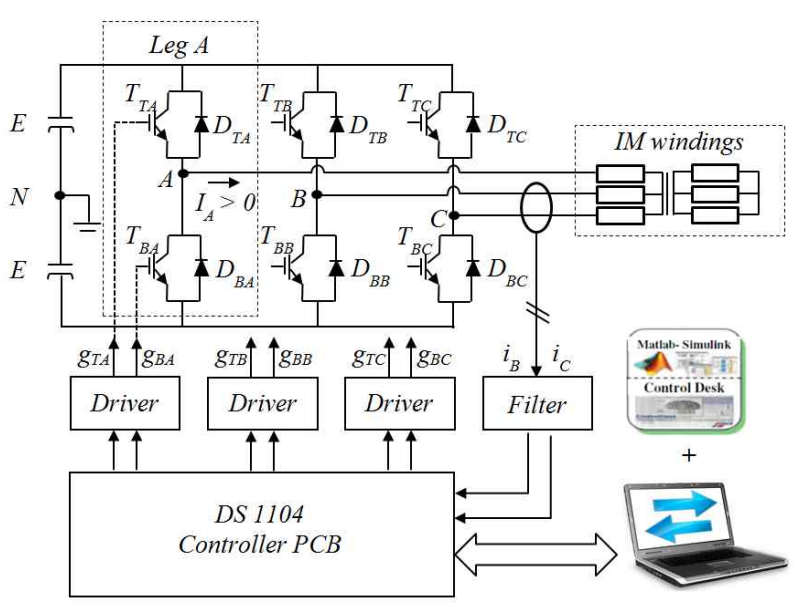

Fig. 3. Basic circuit of a three-phase six-switch VSI-fed induction motor based on DS1104.

expressions

$$
\hat{\omega}_{s}^{(s)}=\frac{\frac{\mathrm{d} \hat{\psi}_{r \alpha}^{(s)}}{\mathrm{d} t} \hat{\psi}_{r \beta}^{(s)}-\frac{\mathrm{d} \hat{\psi}_{r \beta}^{(s)}}{\mathrm{d} t} \hat{\psi}_{r \alpha}^{(s)}}{\hat{\psi}_{r}^{(s) 2}}
$$

and

$$
\hat{\psi}_{r}^{(s)}=\frac{x_{r}^{\prime}}{x_{m}}\left(\hat{\psi}_{s}^{(s)}-x_{s}^{\prime} i_{s}^{(s)}\right) .
$$

The slip speed can be calculated by dividing the estimated motor torque by the square of rotor flux.

$$
\hat{\omega}_{\text {slip }}^{(s)}=\frac{2 \omega_{b} \hat{R}_{s} \hat{T}_{m}^{(s)}}{3 P \psi_{r}^{(s) 2}} .
$$

The estimated electromagnetic torque can be derived from Equation (2), where the estimated stator flux and the measured stator currents are used

$$
\hat{T}_{m}^{(s)}=\frac{3}{2} \frac{P}{2 \omega_{b}}\left(\hat{\psi}_{s \alpha}^{(s)} i_{s \beta}^{(s)}-\hat{\psi}_{s \beta}^{(s)} i_{s \alpha}^{(s)}\right) .
$$

The superscript $(s)$ denotes the stator orientation reference frame.

\section{ONLINE INVERTER NONLINEARITY ESTIMATION AND COMPENSATION}

PWM-VSIs have a highly nonlinear characteristic in low-speed operating modes for AC drives; this characteristic causes distortion in the terminal voltage and generates instability in the control loop. The most recognized inverter nonlinearities are due to the behavior of power devices and the blanking time necessary to prevent DC-link short circuit. Fig. 3 shows the basic circuit of a three-phase six-switch VSI-fed induction motor based on a DS1104 controller board. The inverter includes two identical DC sources $(E)$ and six

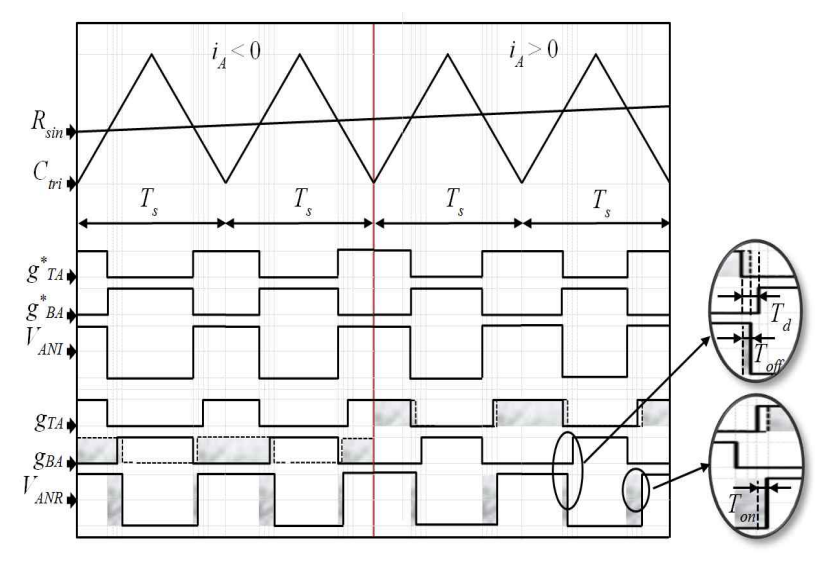

Fig. 4. Actual and ideal waveforms for one-leg PWM implementation.

bidirectional switches. Each switch consists of an IGBT $(T)$ mounted anti-parallel with a freewheeling diode $(D)$. The gate drive signals $\left(g_{T L}, g_{B L}\right)$ are provided by a DS1104 controller board. In practical cases, turn $\mathrm{ON}$ or turn OFF an IGBT requires finite times ( $T_{o n}$ and $T_{o f f}$ ) to be performed. Thus, the consideration of the dead zone $\left(T_{d}\right)$ is compulsory to prevent a DC-link short circuit.

Fig. 4 provides a comparison of the ideal and actual waveforms for one-leg PWM implementation. In the actual implementation, the positive edges of the commanded gate drive signals $\left(g_{T A}^{*}, g_{B A}^{*}\right)$ are delayed with $T_{d}$ although the negative edges are maintained. The effective output voltage $V_{A N R}$ is shifted due to the $T_{\text {on }}$ and $T_{\text {off }}$ of the power devices. Moreover, the effect of IGBT saturation voltage $V_{\text {sat }}$ and diode forward voltage drop $V_{f}$ is exhibited in the peak-to-peak actual voltage.

Overall, each phase output voltage $\left(V_{L N R}\right)$ can be synthesized as follows:

$$
V_{L N R}=\left\{\begin{array}{l}
\left(V_{d c}-V_{s a t}+V_{f}\right)\left(S_{T L}-\frac{1}{2}\right)-\frac{1}{2}\left(V_{s a t}+V_{f}\right) \text { if } i_{L} \geq 0 \\
\left(V_{d c}-V_{s a t}+V_{f}\right)\left(S_{B L}-\frac{1}{2}\right)+\frac{1}{2}\left(V_{s a t}+V_{f}\right) \text { if } i_{L}<0
\end{array},\right.
$$

where $(L \equiv A, B$, or $C)$ denotes the inverter leg or phase and $V_{d c}$ is the average value of the DC-link voltage. $S_{T L}$ and $S_{B L}$ are the effective top and bottom switching signals represented as

$$
\begin{aligned}
& S_{T L}=g_{T L} O R g_{T L\left(T_{O f f}-T o n\right)} \\
& \left.S_{B L}=g_{B L} N O R g_{B L(T o f f-T o n}\right)
\end{aligned}
$$

and

$$
\begin{aligned}
& g_{T L}=\left[g *{ }_{T L} A N D g *{ }_{T L(T d)}\right]_{(T o n)} \\
& g_{B L}=\left[g^{*} T L N O R{ }^{*} T L(T d)\right]_{(T o n)}
\end{aligned}
$$

where $g_{T L}$ and $g_{B L}$ are the gate drive signals after shifting 


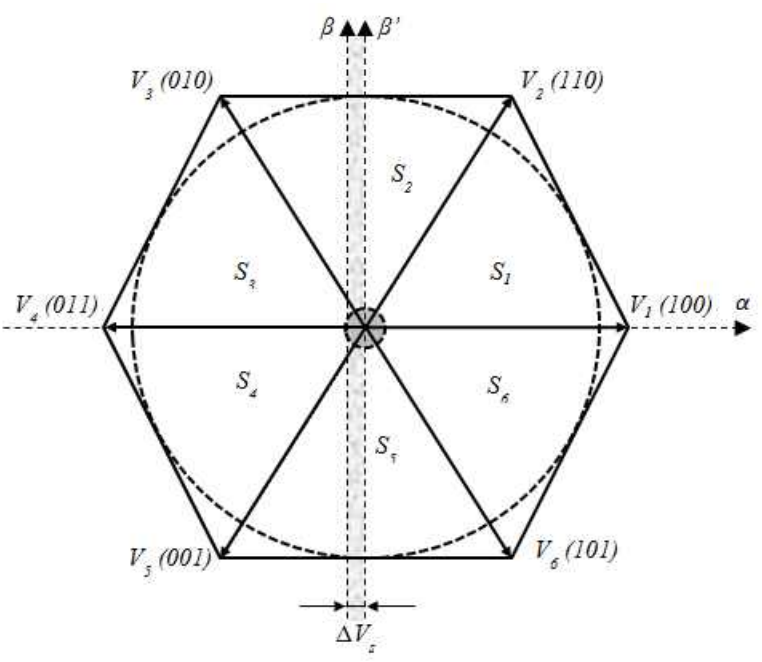

Fig. 5. Space vector diagram of the effect of inverter nonlinearities on output voltage.

with $T_{\text {on }}$.

Thus, the synthesis of $V_{L N R}$ is based on the following three considerations.

- Behavior of the used switches

- States of the gate drive signals $\left(g_{T L}, g_{B L}\right)$

- Motor current direction $\left(i_{L}\right)$

The ideal output voltage is calculated with only the upper commanded gate drive signals $\left(g_{T L}^{*}\right)$ and $V_{d c}$ as follows:

$$
V_{L N I}=V_{d c}\left(g_{T L}^{*}-0.5\right) \text {. }
$$

After comparing Equations (28) and (31) over several switching periods $\left(T_{s}\right)$, an offset in the output voltage waveform of each inverter leg $\left(V_{A N R}, V_{B N R}, V_{C N R}\right)$ is observed. Thus, a voltage error $(\Delta V)$ appears in the space vector diagram as shown in Fig. 5.

An adaptive method based on MRAS is performed to estimate and compensate for the aforementioned error. The proposed MRAS involves two flux-linkage models in stationary reference frame $(\alpha, \beta)$. The first does not include $T_{d}$, $T_{\text {on }}$, and $T_{\text {off }}$ as the reference model, whereas the second includes as an adjustable model. The block diagram of the proposed technique is shown in Fig. 6.

The stator flux estimation under ideal voltage is given as

$$
\frac{\mathrm{d} \psi_{L I}}{\mathrm{~d} t}=V_{L N I}-R_{S} \omega_{b} i_{L I} .
$$

Similarly, the adapted flux model can be presented using the estimated real output voltage as follows:

$$
\frac{\mathrm{d} \psi_{L R}}{\mathrm{~d} t}=V_{L N R}-R_{S} \omega_{b} i_{L R} .
$$

Similar to [24], the relationship between the reference and actual duty cycle signals $\left(d_{L,}^{*} d_{L R}^{*}\right)$ is established as

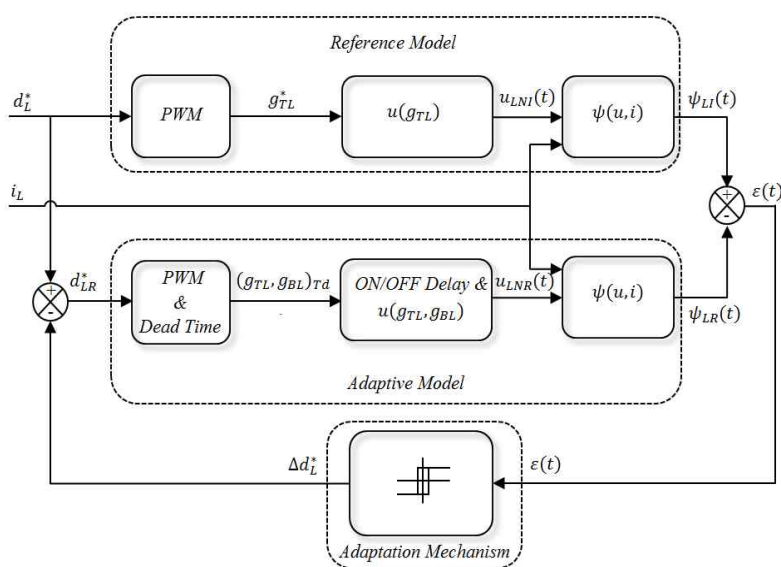

Fig. 6. MRAS based inverter nonlinearities estimation.

$$
d_{L R}^{*}=d_{L}^{*}-\Delta d_{L}^{*},
$$

where

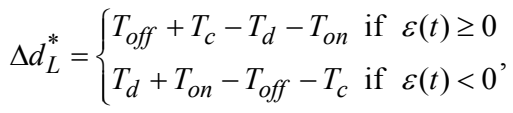

$T_{c}$ is an estimated time that can be used to control the average error of the output voltage [24].

$$
T_{c}=T_{d}+T_{o n}-T_{o f f}+\frac{T_{s}}{V_{d c}}\left(V_{s a t 0}+V_{f 0}\right)
$$

$V_{\text {sat } 0}$ and $V_{f 0}$ are the threshold voltages of the IGBT and anti-parallel diodes respectively (shown in Appendix 2).

\section{Simulation RESUlts}

A computer simulation is conducted to determine the features of the proposed algorithms. A flux-linkage-based model for a $0.9 \mathrm{Kw}$, two-pole pair squirrel cage induction motor is used. The motor specifications and data are listed in Appendix 1. The switching frequency is set to $2.5 \mathrm{kH}$, and the sampling period is $70 \mu \mathrm{s}$. However, when the inverter nonlinearities are introduced, the sampling period is reduced to $4 \mu \mathrm{s}$, which represents the dead time value $\left(T_{d}\right)$. The flux reference value is obtained based on its equivalent voltage $\left(\psi_{s}=540 \mathrm{~V}\right)$. Observer gain $k_{c}$ and both $k_{P}$ and $k_{I}$ are set as $k_{c}=$ $510, k_{P}=1$, and $k_{I}=1000$.

Fig. 7 shows the estimated stator flux components $(d, q)$ as well as flux amplitude and angle at low speed (15 rpm) with full-load test $(6 \mathrm{~N} . \mathrm{m})$. The flux estimation error is likewise shown in the same figure. The line current waveforms at $4 \mathrm{~Hz}$ with and without nonlinearity compensation are shown in Fig. 8. Amplitude, frequency and THD are given with an FFT analysis tool, which is available in Matlab/Simulink.

Overall, the observed value replicates well the actual one since the estimation error converges to zero. Moreover, the current waveform is improved by means the MRAS 

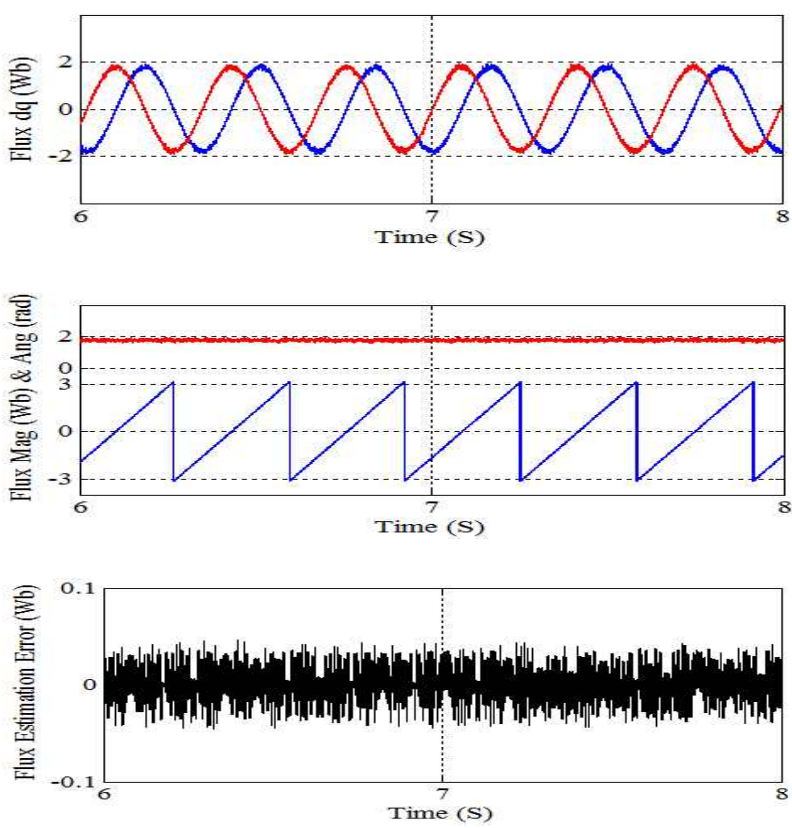

Fig. 7. Simulation results at $15 \mathrm{rpm}$ with full load (6 N.m). From top to bottom: stator flux components $(d q)$, flux magnitude, flux angle, and estimation error.
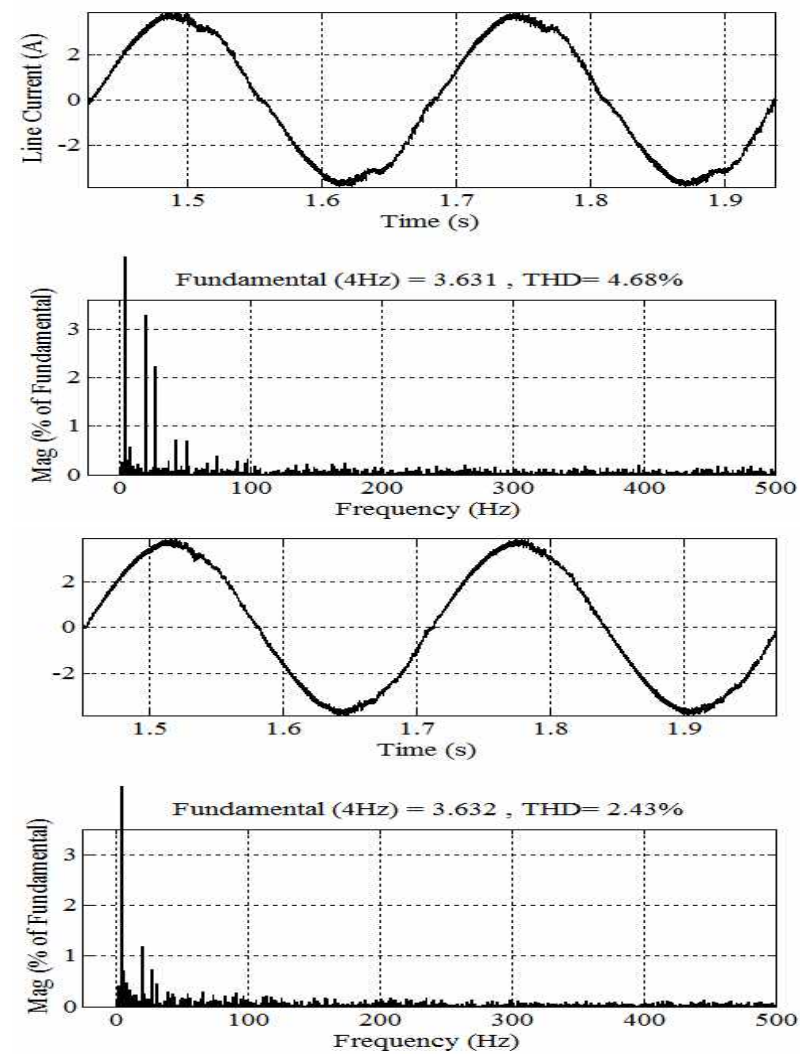

Fig. 8. Simulation results at $4 \mathrm{~Hz}$. From top to bottom: waveforms and spectres of one-line current without and with compensation.

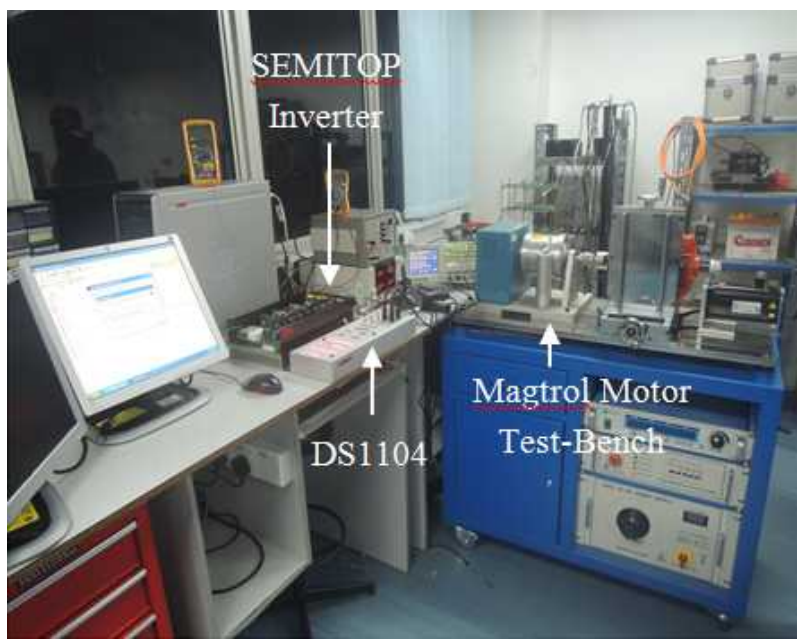

Fig. 9. Experimental setup.

algorithm; this result is verified by the decrease in THD. On the other hand, the proposed method is more reliable than other simple methods as in [30] since it combines the merits of both current- and voltage-based techniques. In fact, the proposed method has the robustness of the voltage feedback method and compensates the motor current effect by comparing the actual and ideal line currents $\left(i_{L I}\right.$ and $\left.i_{L R}\right)$.

\section{EXPERIMENTAL RESULTS}

The effectiveness of the proposed algorithm is verified with an arranged experimental setup (Fig. 9). A high-speed TMS320F240 digital signal processor is well suited to implement the whole algorithm; a program code is created using Matlab/Simulink software. The controller signals are sent to a SEMITOP inverter (manufactured by SEMIKRON $R \& I)$ in order to control the induction motor. It is noted that the similar motor specifications and data are used in the simulation and experiments. The inverter parameters are available in the manufacturer data sheet (see Appendix 2). The induction motor is tested with a DSP6000-based programmable test bench under different operating conditions. The obtained results are displayed by a LeCroy Wavesurfer 24MXs-B oscilloscope. The switching frequency is set to $2.5 \mathrm{kH}$ for all experiments.

A no-load test at $300 \mathrm{rpm}$ is firstly performed to evaluate the proposed SMO at high speeds. Fig. 10 shows the estimated stator flux components $(d, q)$ and their circular trajectory. The flux magnitude and angle in steady state are also shown in the figure.

From Fig. 10, it can be seen the similar waveforms compared to those of classical methods. However, the observation accuracy should be valued. Given the unavailability of the flux sensor, accuracy was verified using the speed estimation error. Fig. 11 shows the measured and 

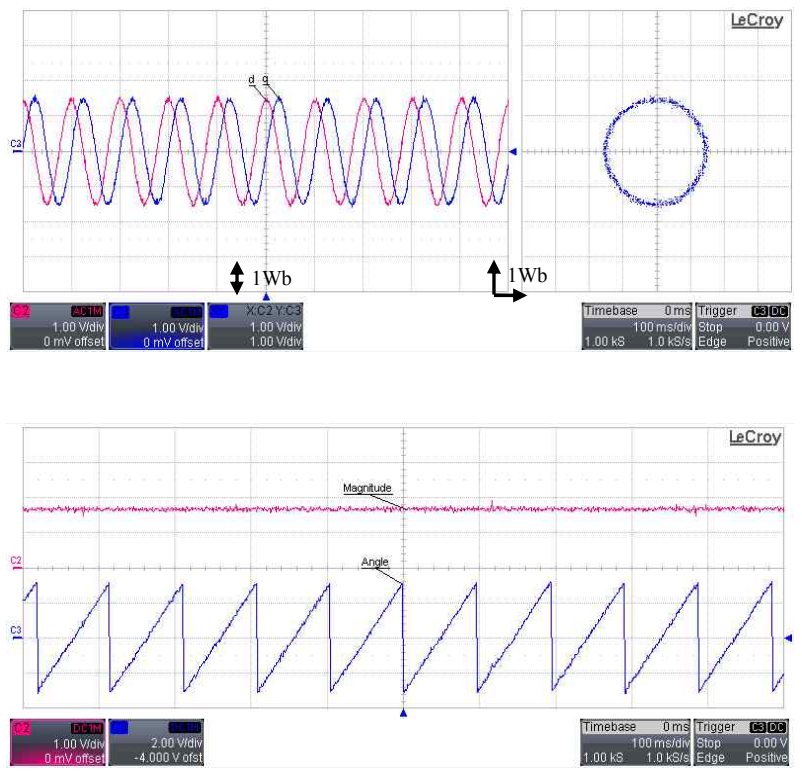

Fig. 10. Experimental results for no-load test at $300 \mathrm{rpm}$. From top to bottom: stator flux components $(d q)$ and flux locus, stator flux magnitude, and stator flux angle.

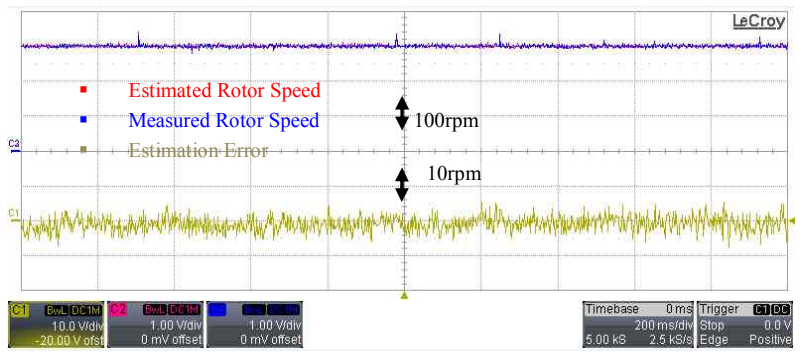

Fig. 11. Experimental results for measured and actual motor speed comparison at $300 \mathrm{rpm}$.

estimated rotor speed at $300 \mathrm{rpm}$. The speed error signal is also presented in the same figure. The above result indicates that the proposed SMO is accurate because the speed equation (extracted from Equations (23) and (26)) was based on the rotor-flux estimated value.

In second step, a speed reverse test at $\pm 150 \mathrm{rpm}$ ( $\pm 10 \%$ of the synchronous speed) is performed. The motor is operated for $5 \mathrm{~s}$ at $+150 \mathrm{rpm}$ in motoring mode and then reversed to $-150 \mathrm{rpm}$ while the torque is almost unchanged (braking mode). Fig. 12 shows the estimated rotor speed and position. The stator current is also presented. Other experiments at low speeds $( \pm 30 \mathrm{rpm})$ are also conducted. Fig. 13 shows the speed estimation error as well as actual and estimated rotor speeds. The transient periods of speed when the speed reference is changed from $300 \mathrm{rpm}$ to $30 \mathrm{rpm}$ are shown in the same figure. The rotor electrical angle is likewise presented. Overall, the proposed SMO follows the actual value under all operating conditions, at high, medium, and even low speed

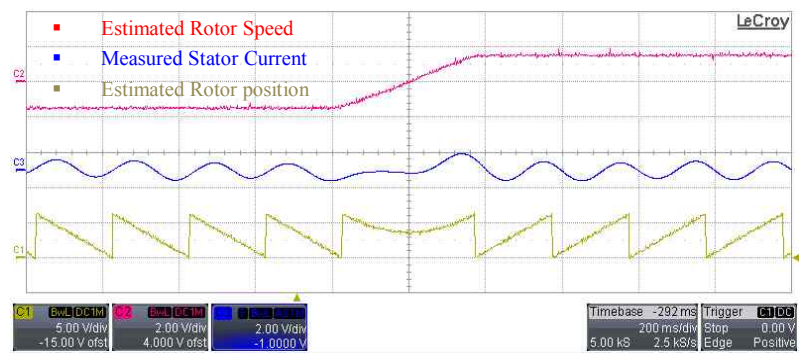

Fig. 12. Experimental results at $\pm 150 \mathrm{rpm}$. From top to bottom: rotor speed $(200 \mathrm{rpm} / \mathrm{div})$, stator current $(5 \mathrm{~A} / \mathrm{div})$, rotor position $(5 \mathrm{rad} / \mathrm{div})$.
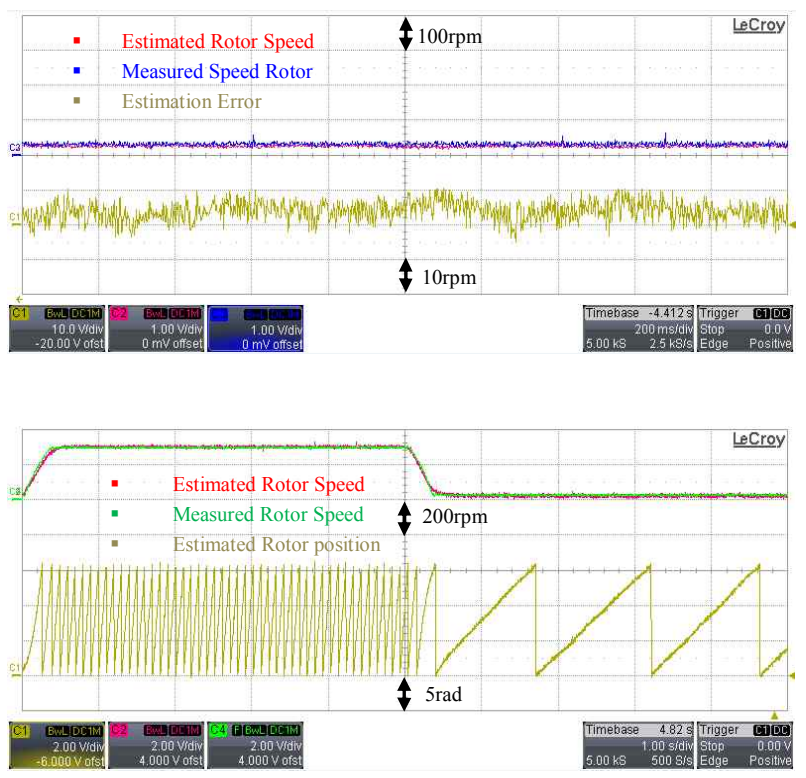

Fig. 13. Experimental results. From top to bottom: rotor position and estimated and actual rotor speeds during the reversal.

ranges. During reversal, the speed estimation error remains acceptable. This finding indicates that the flux observer is insensitive to speed reversal. On the other hand, the current waveforms of the simulation and experimental results exhibit a similarity despite the neglect of all discretization and delays in the continuous models. This result reflects the suitability of the DS1 104 features in such drive.

\section{CONCLUSIONS}

An experimental investigation of robust and speed-sensorless SMO-based stator flux estimation was performed in this study. The proposed SMO was tested with a wide range of speeds for a DTC-SVM induction motor drive. The stability conditions were verified in the context of the Lyapunov theorem. A simple method was adopted because of the need for rotor time-constant adaptation. Moreover, an 
MRAS-based algorithm was introduced to estimate and compensate for the inverter nonlinearities. The feasibility of the whole algorithm was verified by an experimental setup that consists of a DS1104 controller board and a DSP6000 programmable motor test bench.

\section{APPENDIX}

\section{A. Appendix 1}

Motor RATED SPECIFICATIONS AND DATA

\begin{tabular}{|c|c|}
\hline Power & $900 \mathrm{~W}$ \\
Voltage & $380 / 660$ \\
Current & $\mathrm{V} 2.6 \mathrm{~A}$ \\
Frequency & $50 \mathrm{~Hz}$ \\
Torque & $6 \mathrm{~N} \cdot \mathrm{m}$ \\
Speed & $1420 \mathrm{rpm}$ \\
Pole-pairs & 2 \\
$\mathrm{R}_{\mathrm{s}}$ & $21.00 \Omega$ \\
$\mathrm{R}_{\mathrm{r}}$ & $22.63 \Omega$ \\
$\mathrm{x}_{\mathrm{s}}$ & $330.68 \Omega$ \\
$\mathrm{x}_{\mathrm{r}}$ & $339.57 \Omega$ \\
$\mathrm{x}_{\mathrm{m}}$ & $313.00 \Omega$ \\
\hline
\end{tabular}

B. Appendix 2

INVERTER SPECIFICATIONS (From SEMIKRON R\&D DATASHEET)

\begin{tabular}{|c|c|}
\hline $\mathrm{I}_{\mathrm{L}} \max$ & $35 \mathrm{~A}$ \\
$\mathrm{~V}_{\mathrm{dc}} \max$ & $750 \mathrm{~V}$ \\
$\mathrm{~V}_{\mathrm{ce}} \max$ & $1200 \mathrm{~V}$ \\
$\mathrm{~T}_{\mathrm{s}} \max$ & $1 / 15 \mathrm{kHz}$ \\
$\mathrm{V}_{\text {sat0 }}$ & $2.2 \mathrm{~V}$ \\
$\mathrm{~V}_{\mathrm{f0}}$ & $1.8 \mathrm{~V}$ \\
$\mathrm{R}_{\mathrm{ce}}(125 \mathrm{C})$ & $26.10^{-3} \Omega$ \\
$\mathrm{R}_{\mathrm{d}}(125 \mathrm{C})$ & $16.10^{-3} \Omega$ \\
$\mathrm{T}_{\mathrm{d}}$ (hardware) & $4 \mu \mathrm{s}$ \\
\hline
\end{tabular}

\section{ACKNOWLEDGMENT}

This work was supported by the Ministry of Higher Education of Algeria and University of Malaya (Malaysia) under projects UM.C/HIR/MOHE/ENG/D000017-16001 and CG005-2013.

\section{REFERENCES}

[1] D. Casadei, G. Serra, and A. Tani, "Implementation of a direct torque control algorithm for induction motors based on discrete space vector modulation," IEEE Trans. Power Electron., Vol. 15, No. 4, pp. 769-777, Jul. 2000.

[2] C. Lascu, I. Boldea, and F.Blaabjerg, "Direct torque control of sensorless induction motors: a sliding mode approach," IEEE Trans. Ind. Applicat., Vol. 40, No. 2, pp. 582-589, Mar./Apr. 2004.

[3] I. Boldea, M. C. Paicu, G. D. Andreescu, and F. Blaabjerg, "Active flux DTFC-SVM sensorless control of IPMSM," IEEE Trans. Energ. Convers., Vol. 24, No. 2, pp. 314-322, Jun. 2009.
[4] G. Wang, R. Yang, and D. Xu, "DSP-Based Control of Sensorless IPMSM Drives for Wide-Speed-Range Operation," IEEE Trans. Ind. Electron., Vol. 60, No. 2, pp. 720-727, Feb. 2013.

[5] A. Ghaderi and T. Hanamoto, "Wide-speed-range sensorless vector control of synchronous reluctance motors based on extended programmable cascaded low-pass filters," IEEE Trans. Ind. Electron., Vol. 58, No. 6, pp. 2322-2333, Jun. 2011.

[6] D. R. Wrobel, A. S. Budden, D. Salt, D. Holliday, P. H. Mellor, A. Dinu, and P. Sangha, "Rotor design for sensorless position estimation in permanent magnet machines," IEEE Trans. Ind. Electron., Vol. 58, No. 9, pp. 3815-3824, Sep. 2011.

[7] K. Liu, Q. Zhang, J. T. Chen, Z. Q. Zhu, J. Zhang, and A.W. Shen, "Online multi-parameter estimation of non-salient pole PM synchronous machines with temperature variation tracking," IEEE Trans. Ind. Electron., Vol. 58, No. 5, pp. 1776-1788, May 2011.

[8] T. Orlowska-Kowalska, and M.Dybkowski, "Stator-current based MRAS estimator for a wide range speed-sensorless induction-motor drive," IEEE Trans. Ind. Electron., Vol. 57, No. 4, pp. 1296-1308, Apr. 2010.

[9] C. Lascu, I. Boldea, and F. Blaabjerg, "A Class of speed Sensorless Sliding-Mode Observers for High-Performance Induction Motor Drives", IEEE Trans. Ind. Electron., Vol. 56, No. 9, pp. 3394-3403, Oct. 2009.

[10] Z. Qiao, T. Shi, Y. Wang, Y. Yan, C. Xia, and X. He, "New and Sliding-Mode Observer for Position Sensorless Control of Permanent-Magnet Synchronous Motor," IEEE Trans. Ind. Electron., Vol. 60, No. 2, pp. 710-719, Oct. 2013.

[11] M. S. Jaafarizedah, C. Lascu, and S. Fadali, "State Estimation of Induction Motor Drives Using the Unscented Kalman Filter," IEEE Trans. Ind. Electron., Vol. 59, No. 11, pp. 4207-4216, Nov. 2012.

[12] S. Zaky, "Stability analysis of speed and stator resistance estimators for sensorless inductionmotor drives," IEEE Trans. Ind. Electron., Vol. 59, No. 2, pp. 858-870, Feb. 2012.

[13] M. S. Zaky, M. Khater, H.Yasin, S. S. Shokralla, "Very low speed and zero speed estimations of sensorless induction motor drives," Electric Power Systems Research. Vol. 80, No. 2. 143-151, 2010.

[14] H. Kim, J. Son, and J. Lee, "A High-Speed Sliding-Mode Observer for the Sensorless Speed Control of a PMSM," IEEE Trans. Ind. Electron., Vol. 58, No. 9, pp. 4069-4077, Oct. 2011.

[15] Z. Xu, and M. F. Rahman, "Comparison of a Sliding Observer and a Kalman Filter for Direct-Torque-Controlled IPM Synchronous Motor Drives," IEEE Trans. Ind. Electron., Vol. 59, No. 11, pp. 4179-4188, Oct 2012.

[16] M. L. Corradini, G. Ippoliti, S. Longhi, and G. Orlando, "A Quasi-Sliding Mode Approach for Robust Control and Speed Estimation of PM Synchronous Motors," IEEE Trans. Ind. Electron., Vol. 59, No. 2, pp. 1096-1104, Oct. 2012.

[17] T. Orlowska-Kowalska and M. Kaminski, "FPGA implementation of the multilayer neural network for the speed estimation of the two- mass drive system," IEEE Trans. Ind. Informat., Vol. 7, No. 3, pp. 436-445, Aug. 2011.

[18] Y. Oguz, M. Dede, "Speed estimation of vector controlled squirrel cage asynchronous motor with artificial neural networks", Energy Conversion and Management, Vol. 52, No.1, pp. 675-686, Jan. 2011.

[19] S. Kumar, J. Prakash, P. Kanagazabapathy, “A critical evaluation and experimental verification of Extended Kalman Filter, Unscented Kalman Filter and Neural State 
Filter for state estimation of three phase induction motor," Applied Soft Computing, Vol. 11, No. 3, 3199-3208, Apr. 2011.

[20] J. Guzinski and H. Abu-Rub, "Speed Sensorless Induction Motor Drive with Predictive Current Controller," IEEE Trans. Ind. Electron., Vol. 60, No. 2, pp. 699-709, Feb. 2013.

[21] K. L. Z. Q. Zhu, Q. Zhang, and J. Zhang, "Influence of Nonideal Voltage Measurement on Parameter Estimation in Permanent-Magnet Synchronous Machines," IEEE Trans. Ind. Electron., Vol. 59, No. 6, pp. 2438-2447, Jun. 2012.

[22] K.D. Hoang, Z.Q. Zhu, and M.P. Foster, "Influence and compensation of inverter voltage drop in direct torque-controlled four-switch three-phase PM brushless AC drives," IEEE Trans. Pow. Electron., Vol. 26, No. 8, pp. 2343-2357, Aug. 2011.

[23] R. Munoz, and T.A. Lipo, "On-line dead-time compensation technique for open-loop PWM-VSI drives," IEEE Trans. Pow. Electron., Vol. 14, No. 4, pp. 683-689, Jul. 1999.

[24] H. W. Kim, M. J. Youn, K. Y. Cho, and H. S. Kim, "Nonlinearity estimation and compensation of PWM VSI for PMSM under resistance and flux linkage uncertainty," IEEE Trans. Control Syst. Technol, Vol. 14, No. 4, pp. 589-601, Jul. 2006.

[25] H. B. Zhao, Q. M. Wu, and A. Kawamura, "An accurate approach of nonlinearity compensation for VSI inverter output voltage," IEEE Trans. Pow. Electron., Vol. 19, No. 4, pp. 1029-1035, Jul. 2004.

[26] N. Urasaki, T. Senjyu, K. Uezato, and T. Funabashi, "An adaptive dead-time compensation strategy for voltage source inverter fed motor drives," IEEE Trans. Pow. Electron., Vol. 20, No. 5, pp. 1150-1160, Sep. 2005.

[27] S. Y. Kim, W. Lee, M. S. Rho, and S. Y. Park, "Effective dead-time compensation using a simple vectorial disturbance estimator in PMSM drives," IEEE Trans. Ind. Electron., Vol. 57, No. 5, pp. 1609-1614, May 2010.

[28] S. H. Hwang and J. M. Kim, "Dead time compensation method for voltage-fed PWM inverter," IEEE Trans. Ener. Conver., Vol. 25, No. 1, pp. 1-10, Mar. 2010

[29] M. A. Herran, J. R. Fischer, S. A. Gonzalez, M. G. Judewicz, and D. O. Carrica, "Adaptive dead-time compensation for grid-connected PWM inverters of single-stage PV systems," IEEE Trans. Pow. Electron., Vol. 28, No. 6, 2816-2825, Nov. 2013.

[30] Blaabjerg, J.K. Pedersen, and P. Thoegersen, "Improved modulation techniques for PWM-VSI drives," IEEE Trans. Ind. Electron., Vol. 44, No. 1, pp. 87-95, Feb. 1997.

[31] O. Chee-mun, Dynamic simulation of electric machinery using MATLAB/SIMULINK, Prentice hall PTR, New Jersey, 1998.

[32] V. I. Utkin, Sliding Mode in Control and Optimization, Springer Verlag, 1992.

[33] M. Di Lella, and R. Ramin, Semi-Top Technical Information, Semikron, Version. 2, 2008

[34] L. Baghli, H. Razik, and A. Rezzoug, "A stator flux oriented drive for an induction motor with extra $(\alpha, \beta)$ coils," in Conf. Rec. IECON'98, Vol. 4, pp. 2522-2526, Sep. 1998.

[35] M. E. Ahmed and S. Mekhilef, "Design and implementation of a multilevel three-phase inverter with less switches and low output voltage distortion," Journal of Power Electronics, Vol. 9, No. 4, pp.594-604, Jul. 2009.

[36] M.N. Abdul Kadir, S. Mekhilef, and H. W. Ping, "Dual vector control strategy for a three-stage hybrid cascaded multilevel inverter," Journal of Power Electronics, Vol.10, No. 2, pp.155-164, Mar. 2010
[37] M. K. Menshawi and S. Mekhilef, "Multi Stage Inverters Control using Surface Hysteresis Comparators," Journal of Power Electronics, Vol. 13, No. 1, pp.59-69, Jan. 2013.

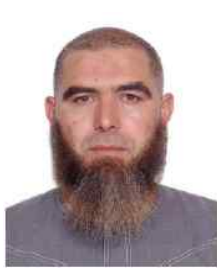

Ahriche Aimad was born in Algiers, Algeria. $\mathrm{He}$ received his B.S. degree in electrical engineering from the University of Jijel, Jijel, Algeria, in 2002 and his Magister degree in electrical engineering from the University of Boumerdes, Boumerdes, Algeria, in 2008. $\mathrm{He}$ has been with the Department of Maintenance, University of Boumerdes, Algeria, since 2008. His current research interests include power converters, $\mathrm{AC}$ drives, and renewable energy.

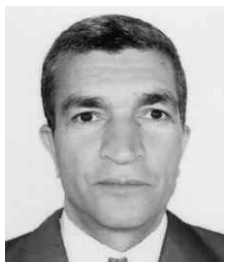

Kidouche Madjid was born in Bordj-Menaiel, Algeria, in 1955. He received his M.Sc. and Ph.D. degrees in electrical engineering from the University of Pennsylvania, USA. He has been with the Department of Automation, University of Boumerdes, Algeria, since 1990. He is a professor in the said institution. His current research interest is in the area of control systems, with emphasis on nonlinear and large-scale dynamical systems.

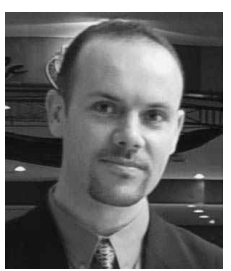

Saad Mekhilef (M'01, SM'12) received his B.S. degree in electrical engineering from the University of Setif, Setif, Algeria, in 1995 and his M.S. and Ph.D. degrees in engineering science from the University of Malaya, Kuala Lumpur, Malaysia, in 1998 and 2003, respectively. He is currently the Deputy Dean and a professor at the Department of Electrical Engineering, University of Malaya. He is the author and co-author of more than 150 publications in international journals and proceedings. He is actively involved in industrial consultancy for major corporations in the power electronics field. His current research interests include power conversion techniques, control of power converters, renewable energy, and energy efficiency. 